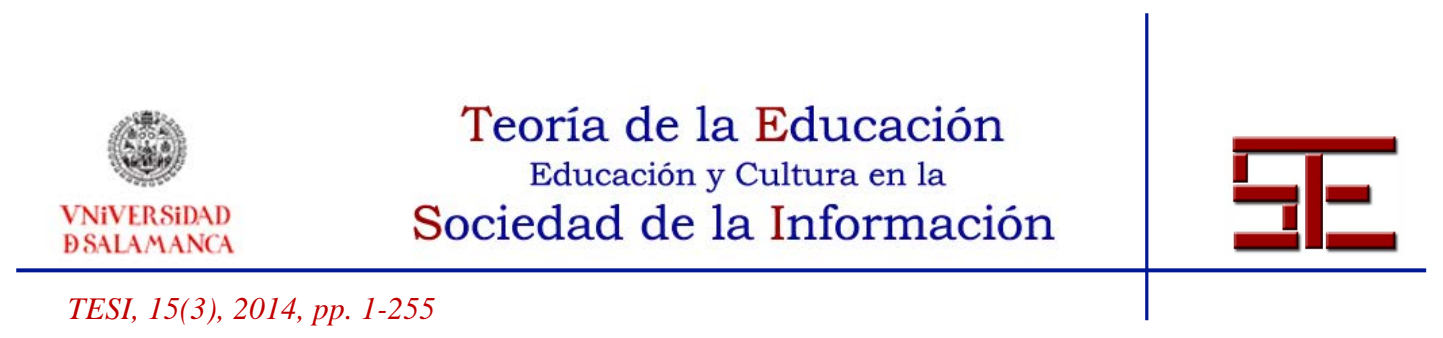

\title{
CÓMO CAMBIAR LAS CONDUCTAS PASIVAS EN EL AULA
}

\author{
Marina CAMARASA \\ RIUS \\ Departamento de Electricidad, \\ Electrónica, Automática y Física \\ Aplicada. \\ Escuela Técnica Superior de \\ Ingeniería y Diseño Industrial \\ (E.T.S.I.D.I.) \\ Universidad Politécnica de Madrid \\ (U.P.M.) \\ marina.camarasa@upm.es
}

\author{
Agustina BRAVO \\ MALO \\ Departamento de Electricidad, \\ Electrónica, Automática y Física \\ Aplicada. \\ Escuela Técnica Superior de \\ Ingeniería y Diseño Industrial \\ (E.T.S.I.D.I) \\ Universidad Politécnica de Madrid \\ (U.P.M.) \\ agustina.bravo@upm.es
}

\author{
J. Mario GARCÍA \\ Departamento de Electricidad, \\ Electrónica, Automática y Física \\ Aplicada. \\ Escuela Técnica Superior de \\ Ingeniería y Diseño Industrial \\ (E.T.S.I.D.I.) \\ Universidad Politécnica de Madrid \\ (U.P.M.) \\ juanmario.garcia@upm.es
}

\section{Resumen:}

Uno de los objetivos que se pretende alcanzar en una educación integral es conseguir que el estudiante esté en disposición de afrontar el aprendizaje por sí mismo a lo largo de la vida. En el presente trabajo se analizan las pautas de actuación docente del profesor en el aula con el objetivo de influir en la motivación e interés de los estudiantes por aprender. Se describen algunas de las metodologías motivadoras que vienen desarrollándose en algunas asignaturas desde que se implantó el nuevo Plan de Estudios en la Escuela Técnica Superior de Ingeniería y Diseño Industrial (ETSIDI) de la Universidad Politécnica de Madrid (UPM) en el año 2010. En concreto se utilizan distintas estrategias de aprendizaje dependiendo del grupo al que van dirigidas. Se ha trabajado en 4 asignaturas, 2 de primer curso y otras 2 de segundo. Se ha analizado el rendimiento académico en algunos grupos de las asignaturas de Física I, Física II, Termodinámica y Transmisión del Calor, donde se ha trabajado con técnicas motivadoras y los resultados muestran un satisfactorio grado de éxito al compararlo con otros grupos análogos de la misma asignatura.

Palabras clave: Motivación, Metodologías activas, Estrategias de aprendizaje.

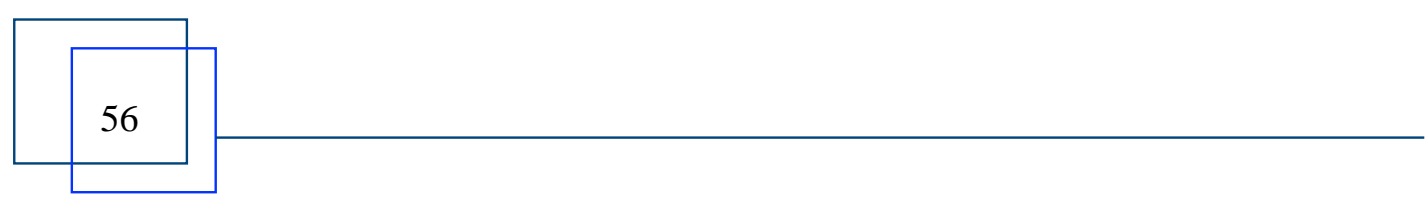




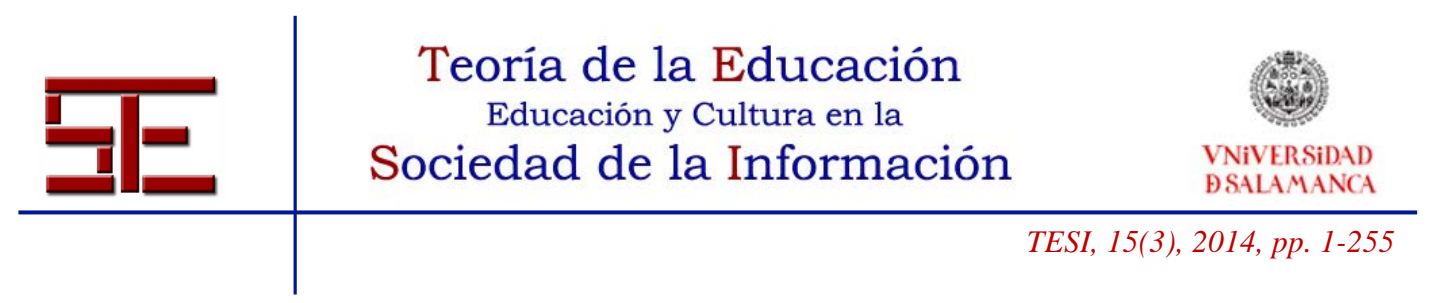

\title{
CHANGING PASSIVE BEHAVIOUR IN THE CLASSROOM
}

\begin{abstract}
:
One of the objectives to be attained in a comprehensive education is to enable the student to tackle the lifelong learning process by itself. In this study some guidelines for teaching actions in the classroom are analysed in order to encourage the interest of students in learning. We describe the motivating methodologies that have been applied in some subjects since 2010 when the new curriculum was implemented in the School of Industrial Design and Engineering (ETSIDI) of the Technical University of Madrid (UPM). Different learning strategies depending on the group being addressed are used. Work has been done specifically in four subjects, two in the first year and two other in the second year of studies. The academic performance of students in some course groups of the subjects Physics I, Physics II, Thermodynamics and Heat Transmission, that have worked with motivational techniques are analysed showing a satisfactory degree of success when compared with other similar groups that do not use such techniques.
\end{abstract}

Key words: Motivation, Active methodologies, Learning strategies. 


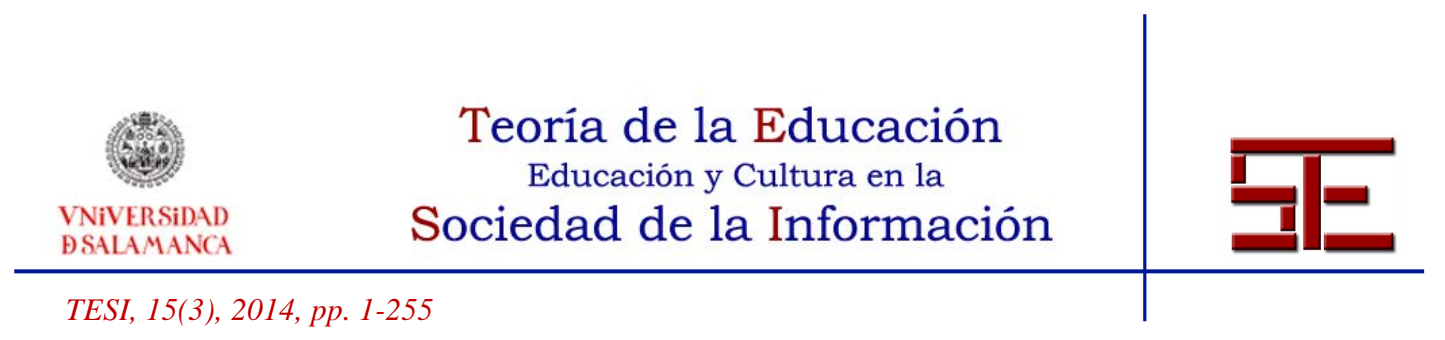

\section{INTRODUCCIÓN}

Desde que se inició el proceso de Bolonia es cada vez mayor la preocupación de la comunidad universitaria por innovar, pero debe entenderse no solo como proceso de hacer cosas nuevas y diferentes, es necesario analizar las acciones positivas que se han venido realizando desde hace años, adaptándolas a la realidad de los nuevos tiempos y de los nuevos estudiantes e incorporando otras diferentes cuyo resultado final vaya dirigido hacia un aprendizaje más eficaz.

Una educación integral del estudiante debe conseguir formar adecuadamente profesionales en áreas de su competencia (Morales, 2009; Asensio, 2012). Además se debe garantizar que el individuo alcance las capacidades necesarias para saber gestionar y contrastar todos los conocimientos, las habilidades, los métodos y los procedimientos adquiridos (Romero y Pérez, 2009).

La incorporación de procesos didácticos en la enseñanza superior permite desarrollar habilidades intelectuales en el individuo además de promover actitudes positivas y valores que le permitirán enfrentarse a su futuro ejercicio profesional. La utilización de estrategias de aprendizaje (EA) fomenta la motivación y permite que el estudiante adquiera una responsabilidad en su propio proceso de aprendizaje (alcance un grado de autonomía).

La motivación, que proviene de moverse (latín motivus), es la causa de una acción. El diccionario de la RAE la define como el ensayo mental preparatorio de una acción para animar o animarse a ejecutarla con interés y diligencia. Según recopilación realizada por Montico (2004) la mayoría de los especialistas coinciden en definirla como un conjunto de procesos implicados en la activación, dirección y persistencia de la conducta o bien como el conjunto de estados y procesos internos de la persona que despiertan, dirigen y sostienen una actividad determinada.

Por estrategias de aprendizaje algunos autores entienden el conjunto organizado, consciente y deliberado de pensamientos, acciones y comportamientos que permitan la adquisición de información y su relación con el conocimiento previo (Beltrán, 1995, Bernard, 1999). Otros autores se refieren a ella como aprender a aprender (Gallardo, 2000; Monereo y Castelló, 2001). En general, las investigaciones en el campo de las EA son cada vez más numerosas y reflejan conclusiones bastante homogéneas (Boza y Toscano, 2012) (Gargallo, Suárez y Pérez, 2009) que se pueden resumir diciendo que los estudiantes eligen diferentes estrategias en función del tipo de la materia a estudiar, que utilizan las más eficaces conforme van avanzando en su conocimiento y que alcanzan un mejor rendimiento académico.

Los docentes deben enfrentarse a nuevos retos en su tarea educativa. No basta con la experiencia obtenida a lo largo de los años en su papel de educador como mero transmisor de conocimientos (Burguet y Buxarrais, 2013). Hay que reconocer que la experien-

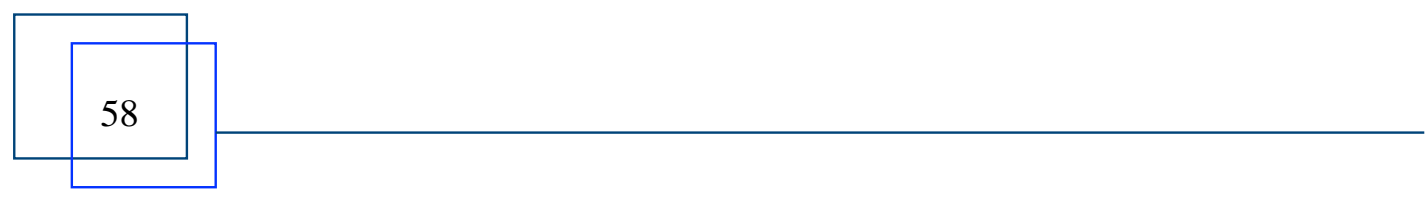




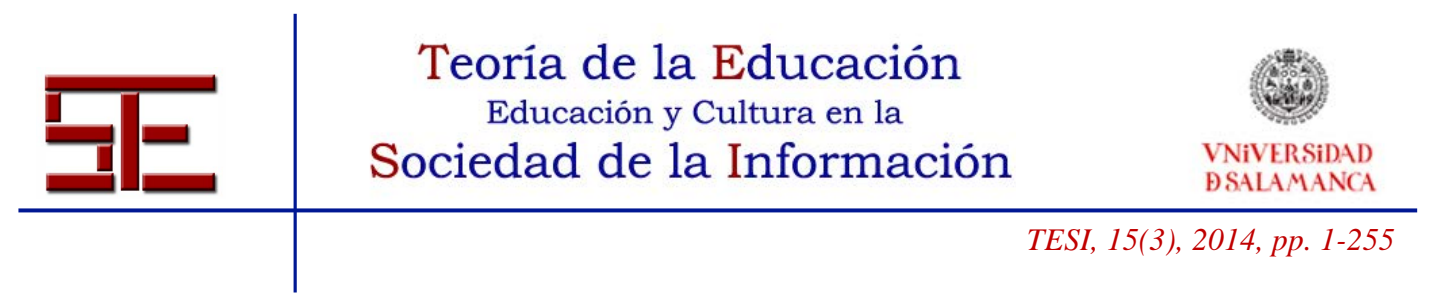

cia no solo se adquiere por tener una trayectoria de muchos años en la enseñanza sino por su actitud frente al reto de enseñar a sus alumnos la capacidad de aprender. Ahora es preciso formarse en competencias que conllevan una nueva forma de entender la función docente y donde los estudiantes adquieren protagonismo.

El profesor puede desarrollar estas nuevas facetas en el aula, poniendo en marcha acciones que promuevan la participación del estudiante, el trabajo en equipo y la capacidad de debatir y solucionar conflictos razonadamente (Buxarrais y Ovide, 2011).

Es trascendental la intervención en el aula, que debe estar basada en una pedagogía de la pregunta más que en una pedagogía de la respuesta, aspecto que ha venido desarrollándose durante muchos años. El afán de conocimiento nace de la pregunta y puede llegar a sorprender al propio individuo. Solo el planteamiento interrogativo puede garantizar un aprendizaje significativo (Alonso, 2005).

Las primeras preguntas siempre deben ir dirigidas al docente: ¿Está motivado el profesor para enseñar? ¿Qué debe hacer para que su actuación resulte eficaz? Preguntas análogas apuntan hacia el estudiante: ¿Está motivado el alumno para aprender? ¿Qué debe hacer para que su estudio resulte eficaz? Sin una respuesta sincera y positiva no se puede abordar la tarea de enseñar ni la de aprender de forma responsable. Todas estas preguntas se irán respondiendo a lo largo del presente trabajo.

Se aprende todo aquello que se practica. El alumno debe hacer, debe hablar, debe escribir... La enseñanza debe ser activa y bidireccional; el profesor debe ofrecer una clase con abundantes estímulos de manera que favorezca la actividad de sus alumnos y se encontrarán entonces en disposición de aprender a partir de la propia experimentación. Así se desarrolla un sentimiento de esfuerzo personal y se mantiene una actitud de superación (Sepúlveda y Rajadell, 2001).

En este trabajo se presenta una recopilación de las distintas EA experimentadas en el aula con asignaturas de distinto nivel. Se hace distinción entre alumnos recién incorporados $\left(1^{\text {er }}\right.$ curso $)$ y los de $2^{\circ}$ curso y se muestra el resultado de la influencia ejercida sobre el rendimiento académico de los estudiantes.

\section{CONTEXTO}

El estudio que se presenta en este trabajo se ha realizado sobre una muestra de estudiantes de la Escuela Técnica Superior de Ingeniería y Diseño Industrial (ETSIDI) de la Universidad Politécnica de Madrid (UPM) y se han clasificado en tres grupos diferenciados: al primero, denominado G1, pertenecen aquellos que acceden por primera vez a la Universidad; el grupo G2 está compuesto por estudiantes de $2^{\circ}$ curso correspondientes a las distintas titulaciones de Grado impartidas en la Escuela; y por último, el grupo

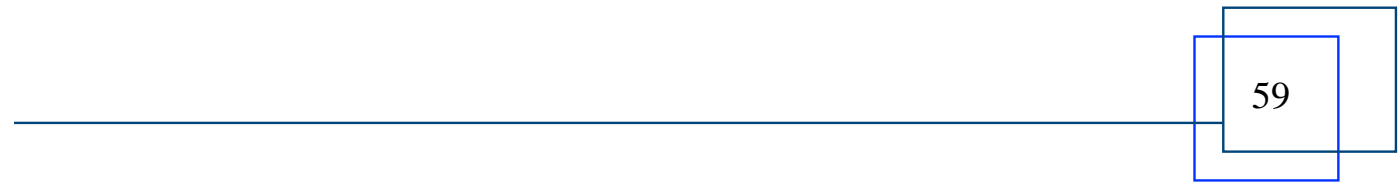




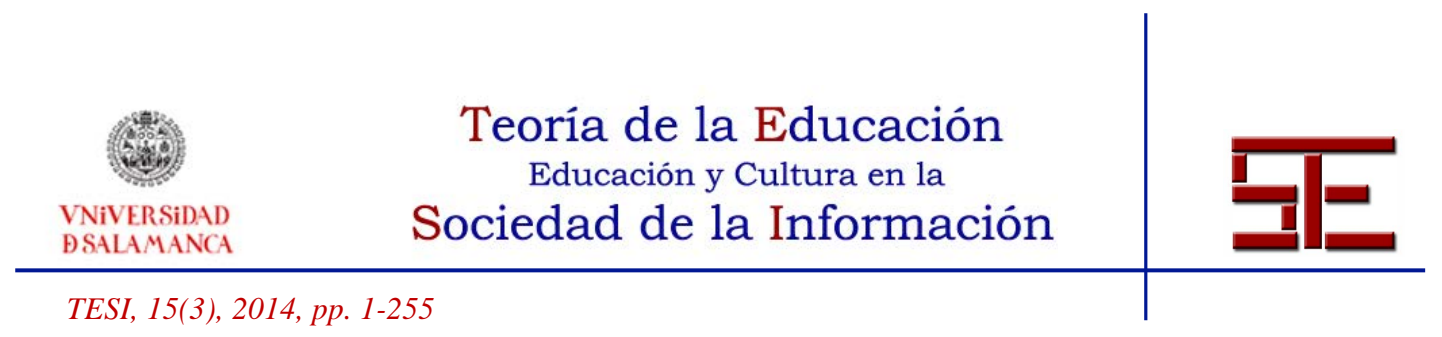

G3 está formado por alumnos ya egresados procedentes de todas las especialidades correspondientes al Plan de Estudios anterior de Ingeniero Técnico Industrial (I.T.I. actualmente en fase de extinción) y que pretenden acceder a los másteres universitarios ofertados. Estos alumnos deben cursar 30 ECTS adicionales como Complementos Formativos, repartidos entre las diferentes asignaturas ofertadas en los Grados, asignaturas que son obligatorias u optativas dependiendo de la especialidad de la titulación ITI de la que procedan.

En el curso 2010-2011 se implantó el nuevo Plan de Estudios adaptado al EEES en la ETSIDI, en 5 titulaciones de Grado: G. en Ingeniería Mecánica (GIM), GI Química (GIQ), GI en Diseño Industrial y Desarrollo de Producto (GID), GI Eléctrica (GIE) y GI Electrónica y Automática (GIA).

Las asignaturas implicadas en esta experiencia vienen reflejadas en la Tabla 1, donde se recoge el nombre de las asignaturas, los grupos definidos anteriormente, semestre al que corresponden, así como el Grado donde se imparten. El tamaño de los grupos suele ser de unos 50 alumnos en las asignaturas de primer curso y más numeroso en las de $2^{\circ}$ curso (en torno a los 80 alumnos por grupo).

Tabla 1. Asignaturas en las que se han aplicado Estrategias de Aprendizaje.

\begin{tabular}{|c|c|c|c|}
\hline $\begin{array}{l}\text { Asignaturas } \\
\text { (ECTS) }\end{array}$ & Grupo & $\begin{array}{l}\text { Curso } \\
\text { (Semestre) }\end{array}$ & Grado* \\
\hline Física I (6) & G1 & $1(1 s)$ & GIM, GID \\
\hline Física II (6) & G1 & $1(2 s)$ & GIM, GID \\
\hline $\begin{array}{l}\text { Termodinámica } \\
(4,5)\end{array}$ & $\mathrm{G} 2+\mathrm{G} 3$ & $2(3 s)$ & $\begin{array}{l}\text { GIM, GIQ, } \\
\text { GIE, GIA }\end{array}$ \\
\hline $\begin{array}{l}\text { Transmisión del Calor } \\
(4,5)\end{array}$ & $\mathrm{G} 2+\mathrm{G} 3$ & $2(4 s)$ & $\begin{array}{l}\text { GIM, GIQ, } \\
\text { GIE, GIA, GID }\end{array}$ \\
\hline
\end{tabular}

*GIM = Grado en Ingeniería Mecánica; GIA = GI Electrónica y Automática; GID = GI Diseño Industrial y Desarrollo de Producto; GIQ = GI Química; GIE = GI Eléctrica

Las 4 asignaturas que se presentan se desarrollan con el mismo programa docente en todas las titulaciones de Grado. La Física I y Física II, correspondientes al primer curso, se organizan en un total de 10 grupos; la Termodinámica, que no se imparte en el GID, se distribuye en 7 grupos y la Transmisión del Calor en 8, todos ellos repartidos en mañanas y tardes. La docencia en el aula utilizando metodologías innovadoras se ha de-

60 


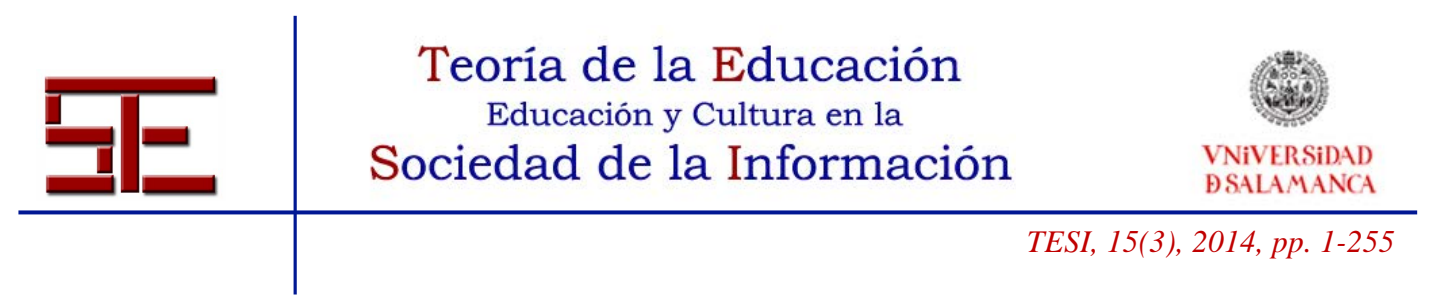

sarrollado en todos los grupos correspondientes a las asignaturas de $2^{\circ}$ curso; sin embargo en las de primer curso solamente se ha trabajado con los grupos de GIM y GID.

La metodología docente a emplear debe adaptarse al grupo al que va dirigido. Aunque las Estrategias de Aprendizaje (EA) puedan ser similares en las distintas asignaturas, deben diseñarse con especial cuidado aquellas que deben cursar los alumnos recién incorporados a la Universidad (Grupo G1); esto es, las correspondientes al primer semestre, que en este estudio es la Física I. Es fundamental "atraer" a los estudiantes desde el principio y para ello deben estar especialmente motivados. El fracaso académico detectado en asignaturas de este nivel suele ser significativo y no se debería atribuir, como es habitual, solamente a la falta de preparación del estudiante; surge más bien un problema de "adaptación" pues no se debe olvidar que estos estudiantes han superado la selectividad y en todas las titulaciones de Grado las notas de corte para acceder son bastante significativas y que, desde que comenzaron a impartirse los Grados, el valor va aumentando gradualmente cada año en esta Escuela.

Por otro lado, al grupo G2 corresponden las asignaturas obligatorias de Termodinámica y de Transmisión del Calor que se imparten en $2^{\circ}$ curso de cada Grado. Los alumnos de este grupo suelen estar más motivados y se encuentran en disposición de afrontar tareas de manera más autónoma que los de primer curso. El último grupo, G3, aunque engloba estas mismas asignaturas, el alumnado es bastante diferente (egresados). Estos estudiantes están realmente motivados y buscan la satisfacción del "saber hacer" voluntariamente.

\section{ACTUACIÓN EN EL AULA}

Una de las causas del poco aprendizaje de los alumnos es debida a que no estudian, pero no estudian porque no están motivados. Conseguir mejorar el estímulo permite aumentar el interés y disposición al esfuerzo, con lo que sus resultados académicos pueden mejorar incrementando su rendimiento y también, muy importante, su autoestima; el alumno se sentirá más satisfecho consigo mismo.

La motivación no solo depende de los estudiantes, las actitudes y prácticas de los profesores en el aula pueden influir en la motivación (por ejemplo mostrar una actitud permisiva y poco exigente puede conllevar a un desinterés).

El profesor debe ser el orientador del aprendizaje de sus alumnos y no solo un mero transmisor de los conocimientos sobre la materia que imparte (Soler, 2012). Debe construir otra enseñanza basada en conseguir que sea más participativa en lugar de tan pasiva (apática), más apasionada en vez de aburrida, más dialogada y más visual. Y todo esto se puede conseguir comenzando por un ejercicio de autocrítica reflexiva donde el

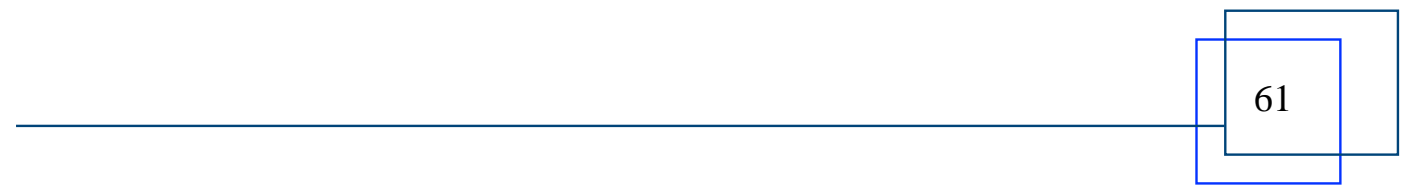




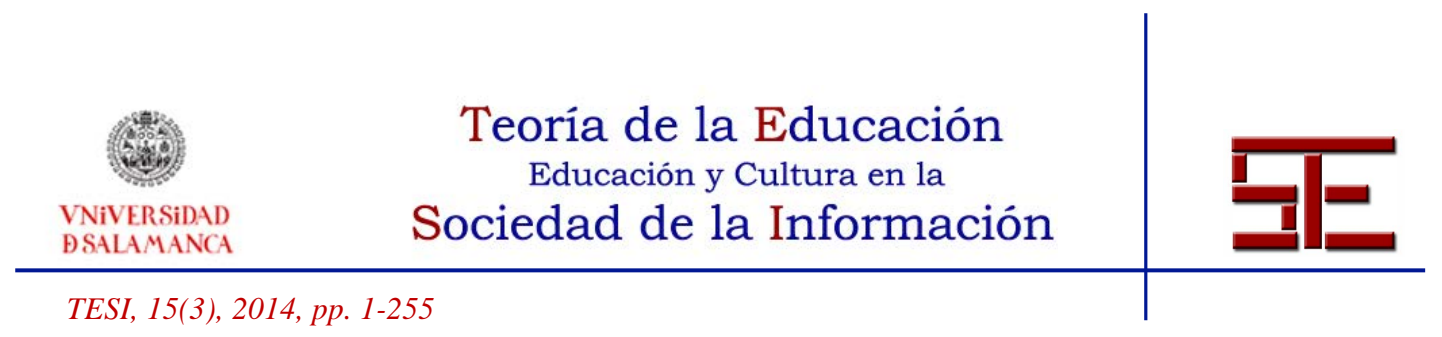

profesor debe revisar tanto los contenidos como los formatos mediante los que organiza su docencia (González, 2002).

El profesor debe desplegar todos los recursos disponibles para ir guiando al estudiante en las distintas etapas de su conocimiento y la manera más eficaz de conseguir que sus alumnos sean cada vez más competentes es provocando un cambio metodológico en el aula. Es preciso definir nuevas formas de trabajar, planificando y organizando y de esta manera se van introduciendo actitudes favorables al aprendizaje.

Las pautas facilitadoras del aprendizaje deben referirse a distintos momentos del proceso de enseñanza. Así, al comienzo de la clase las actuaciones del profesor deben ir dirigidas a captar la atención despertando su curiosidad y mostrando, por ejemplo, la relevancia de lo que van a aprender, presentando información nueva, incierta o sorprendente. Durante el desarrollo se deben crear condiciones para mantener su interés, que deben ir encaminadas a mostrar la aceptación del alumno. A medida que se van introduciendo conceptos nuevos pueden relacionarse con las experiencias o con conocimientos previamente adquiridos. Se debe crear un ritmo fácil de seguir y pueden utilizarse ilustraciones y ejemplos. Los alumnos deben experimentar una cierta percepción de autonomía y un progreso en sus aprendizajes.

Hay que hacer trabajar al alumno y para ello el profesor debe especificar metas que favorezcan el interés. Deben suponer un reto y al mismo tiempo deben ser atrayentes para el estudiante, pero el grado de dificultad debe ser percibido como alcanzable. En resumen, las metas deben ser explícitas, próximas, realistas y medianamente retadoras (García, 2008).

Como señala García (2008), algunas medidas favorecedoras del aprendizaje pueden ser:

Desafío atractivo: Presentar las tareas como una invitación a conseguir algo.

El alumno debe centrar su atención en el proceso y estrategias de una tarea y no tanto en el resultado final (sabe cómo hacerlo aunque en algún caso pueda cometer errores).

Ante una dificultad se debe centrar la atención en la búsqueda de acciones y tácticas que puedan ayudar a resolver el problema.

Los errores y equivocaciones son normales mientras se está aprendiendo; es una ocasión para aprender.

Ambiente de cooperación y no de competitividad.

En definitiva el éxito se puede alcanzar mediante la suma de varios factores como la motivación, las habilidades y un ambiente favorecedor.

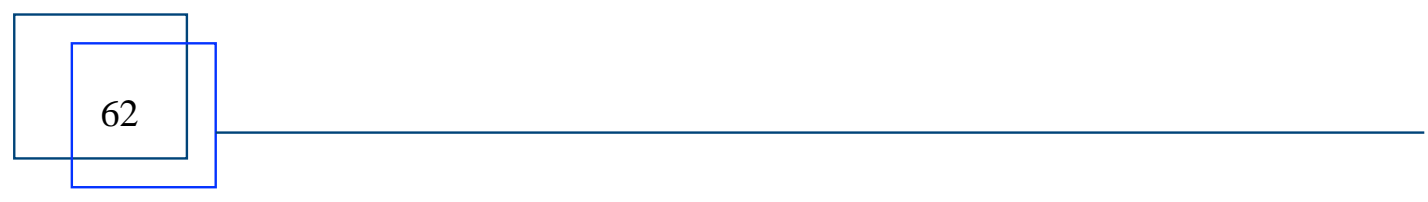




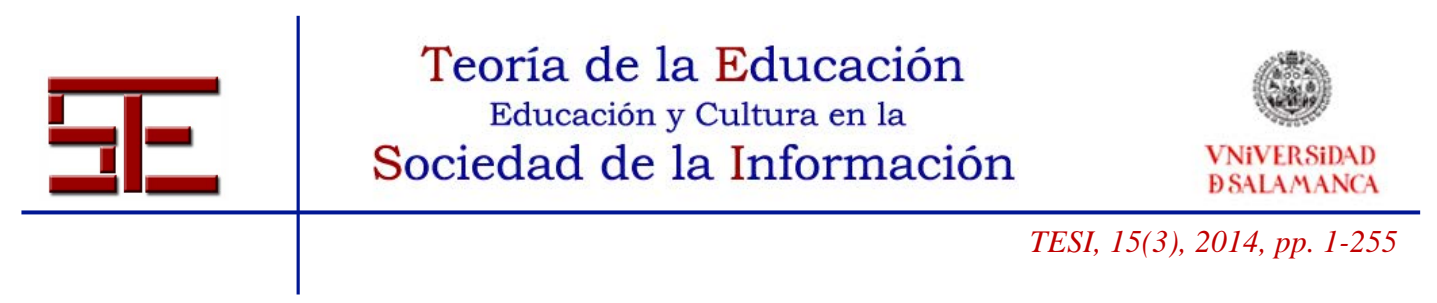

\section{DESCRIPCIÓN DE LAS METODOLOGÍAS Y ESTRATEGIAS}

En este apartado se describen las actividades metodológicas empleadas en el aula que se han llevado a cabo al realizar esta experiencia, todas ellas con la intención de inducir al alumno a estudiar y a trabajar de modo continuado, con el fin de que consigan avanzar en su aprendizaje.

La clase magistral es la metodología más extendida en la formación universitaria y se emplea prácticamente en todas las asignaturas. Si se modifica haciéndola más participativa se conseguirá, además de transmitir conocimientos, que los alumnos vayan adquiriendo hábitos de estudio, vayan perdiendo el miedo a expresarse públicamente y vayan aprendiendo a fijar los conceptos más importantes dentro de cada unidad temática.

\subsection{Las Clases de Teoría}

La técnica de exposición participativa se desarrolla en el aula principalmente por el docente donde presenta información de manera organizada sin importar el tamaño del grupo al que va dirigido. Es importante que el profesor desarrolle habilidades para interesar y motivar a sus alumnos en la exposición y estimular la interacción entre los integrantes; se debe evitar que los estudiantes sean receptores pasivos y con poca interacción. Generalmente se presentan los contenidos con la ayuda de utilización de medios audiovisuales.

La exposición presenta ventajas cuando se pretende dar información general a grupos numerosos de estudiantes y permite dar puntos de vista del docente, motivar a los estudiantes sobre algunos aspectos temáticos, aclarar contenidos difíciles, sintetizar discusiones o debates y responder a interrogantes previos.

En las asignaturas de Física I y Física II se introducen ejemplos sencillos y se hace referencia a aplicaciones de la vida cotidiana. De esta manera la clase magistral se convierte en más participativa y se consigue fijar conceptos.

Durante el transcurso de las exposiciones orales se suele cambiar de actividad, intercalando la técnica de la pregunta (Torre, 2007), donde se plantea al grupo preguntas sencillas de respuesta corta de manera que prácticamente todos los alumnos sepan responder. Con el cambio de actividad se persigue motivar al alumno captando su atención y animándoles a una participación grupal. Esta estrategia desarrolla habilidades para el análisis y síntesis de información y se empieza a trabajar en el aula la competencia de comunicación oral y de trabajo en grupo.

Estas clases ofrecen al estudiante la oportunidad de ser motivados por expertos en el conocimiento de una determinada disciplina. Un buen profesor puede mostrar una asignatura de forma más asequible y con mayor dinamismo que un texto escrito. Es una técnica de comunicación adecuada para aquellos alumnos que quieren escuchar un

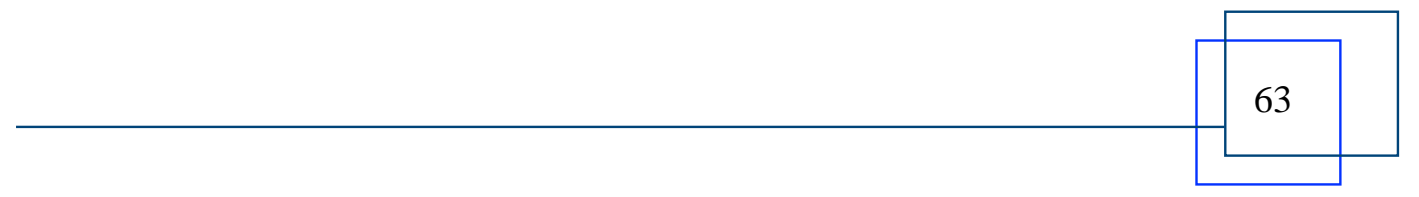




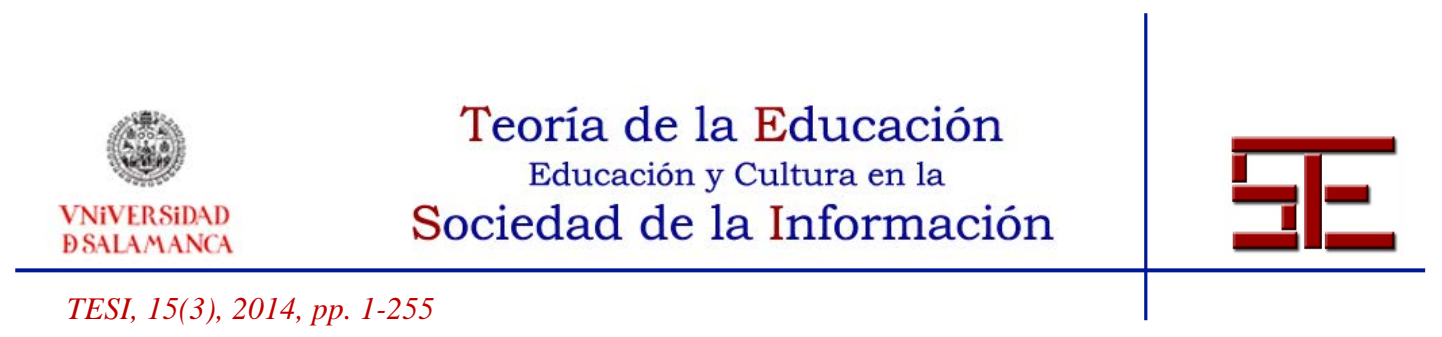

punto de vista nuevo y original sobre una materia en particular.

\subsection{Las Clases de Problemas}

La metodología basada en la resolución de problemas consiste en colocar al estudiante frente a una situación problemática, para la cual tiene que hacer una o más sugerencias de solución. Al poner énfasis en el razonamiento y en la reflexión constituye una poderosa herramienta para aprender puesto que los alumnos tienen que aplicar los conocimientos adquiridos; además inculca el hábito de estudio con espíritu de aprendizaje e indagación.

Con la técnica de Aprendizaje Basado en Problemas (ABP) se induce al estudiante a la reflexión, el análisis, la toma de decisiones y la aplicación de conocimientos vistos previamente; en definitiva, se enfrenta a una dificultad que tiene que resolver (Barkley, Croos y Major, 2007). Esta técnica favorece el desarrollo de habilidades para el análisis y síntesis de información, permite el desarrollo de actitudes positivas ante problemas y desarrolla habilidades cognitivas y de socialización. Además es útil para que los estudiantes identifiquen necesidades en su aprendizaje.

El profesor debe ofrecer retroalimentación asiduamente a sus alumnos sobre su participación en la solución del problema, repasando con el grupo conocimientos, procedimientos, habilidades, etc. El profesor presenta el problema, muestra ejemplos, asesora, facilita y toma parte en el proceso como un miembro más del grupo.

Los estudiantes, juzgan y evalúan sus necesidades de aprendizaje, investigan y desarrollan hipótesis; trabajan individual y grupalmente en la solución del problema; es decir desarrollan competencias para aprender a aprender. Estas acciones cooperativas se suelen realizar en grupos pequeños, en ocasiones de dos compañeros (habitualmente su compañero de mesa) si la disposición del aula no está adaptada para utilizar técnicas grupales.

La resolución de problemas se plantea de diferente manera dependiendo del grupo al que vaya dirigido. A continuación se describe la forma de utilización de esta estrategia en los 3 grupos en los que se ha trabajado.

\subsubsection{Grupo G1}

A este grupo corresponden las asignaturas de Física I y Física II según se puede observar en la Tabla 1. A los alumnos de estas asignaturas se les entrega al comienzo de cada lección una colección de problemas para trabajarlos fuera del aula de manera independiente y voluntaria. El profesor resuelve en clase la mayor parte de ellos a medida que se va desarrollando la materia, dejando que alguno sea resuelto en el aula por algún

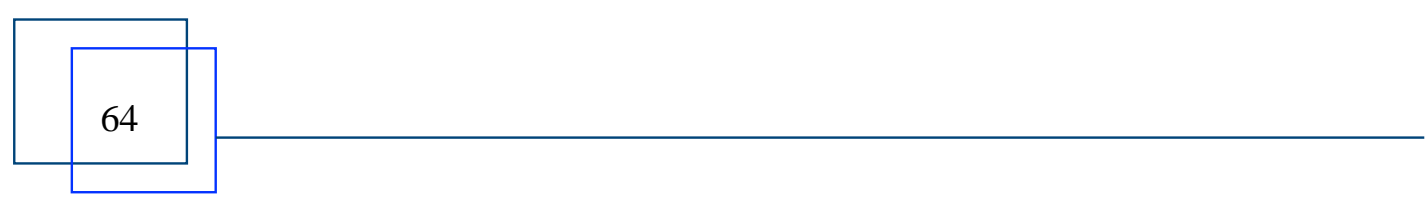




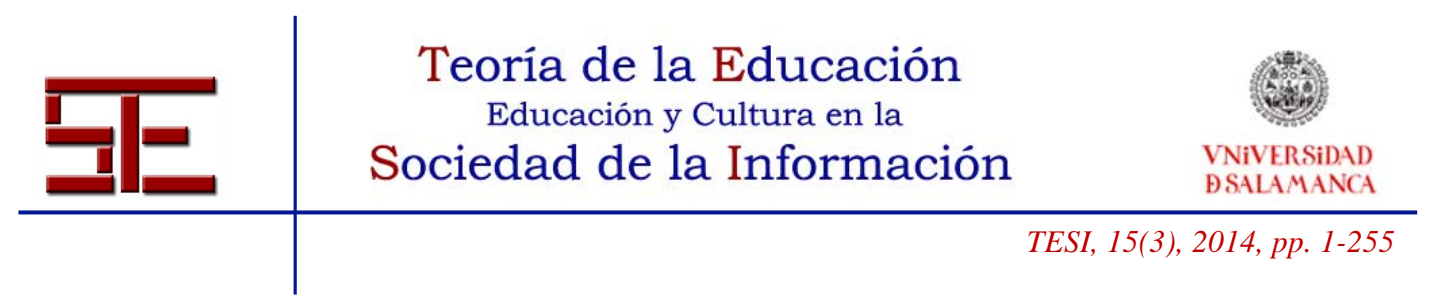

estudiante voluntario que previamente lo había entregado. Al terminar cada tema se les reparte una segunda hoja de problemas que deben entregar en el plazo de una semana. A pesar de que esta actividad no contribuye a la evaluación sumativa la realizan la mayoría de los alumnos.

Otra metodología utilizada en este grupo ha consistido en resolver uno o varios problemas dirigidos que contienen un gran número de apartados donde se incluye la mayor parte de los conceptos teóricos de la lección en estudio y que los alumnos deben entregar de forma voluntaria. De esta manera el alumno ve, con un solo problema, resumida casi toda la teoría del tema particular. Es importante que el alumno pueda sentirse más seguro de sí mismo al entender el problema y le hace perder el miedo a afrontar otro caso nuevo.

Los problemas resueltos por los alumnos y los controles parciales son elementos importantes para evaluar el aprendizaje adquirido por ellos durante el desarrollo de la asignatura.

\subsubsection{Grupo G2}

En las asignaturas de $2^{\circ}$ curso, correspondiente al G2, los alumnos están predispuestos a trabajar de forma más autónoma sin necesidad de hacer su aprendizaje tan dirigido. Es importante desarrollar un procedimiento sistemático en la resolución de problemas, que debe seguir una secuencia: a) definir el problema buscando la información pertinente a partir del enunciado; b) planificar un esquema de resolución; c) escribir los datos conocidos o que se puedan necesitar para cálculos sucesivos; d) dibujar los diagramas adecuados; e) aplicar las leyes correspondientes para obtener una solución numérica y finalmente f) considerar si las magnitudes de los valores numéricos son razonables.

Otra modalidad de la técnica de resolución de problemas empleada con las asignaturas de segundo curso ha consistido en la proposición de problemas que los alumnos deben trabajar individualmente fuera del aula y entregar en la siguiente sesión de clase, donde son resueltos por el profesor en la pizarra. Antes de su resolución, los problemas se reparten al azar entre todos los compañeros y cada uno corrige los errores cometidos y hace anotaciones aclaratorias. Finalmente, se devuelve el ejercicio corregido a cada alumno con las anotaciones pertinentes de su compañero. Esta evaluación entre colegas supone una gran motivación para ellos y perciben esta actividad como gratificante a pesar de que no se califique. Son, en definitiva, evaluaciones formativas cuya finalidad, no se debe olvidar, es que los estudiantes consigan aprender.

$\mathrm{Al}$ principio las tareas suponen para el alumno una barrera que les parece insuperable, están desconcertados, pero a medida que profundizan en el estudio de los problemas se motivan cada vez más y encuentran el trabajo más asequible a pesar de tener un grado de dificultad mayor. Los estudiantes perciben que aprenden, notan que alcanzan un

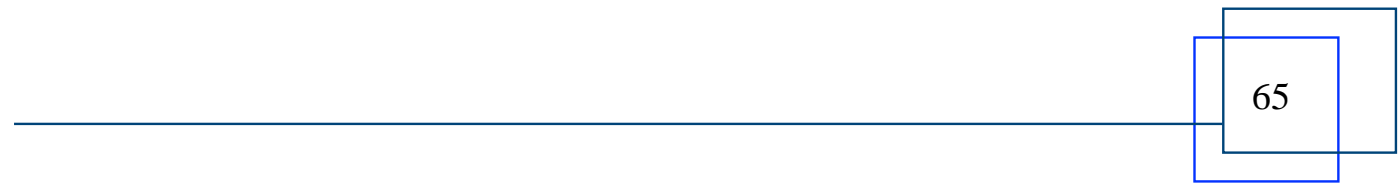




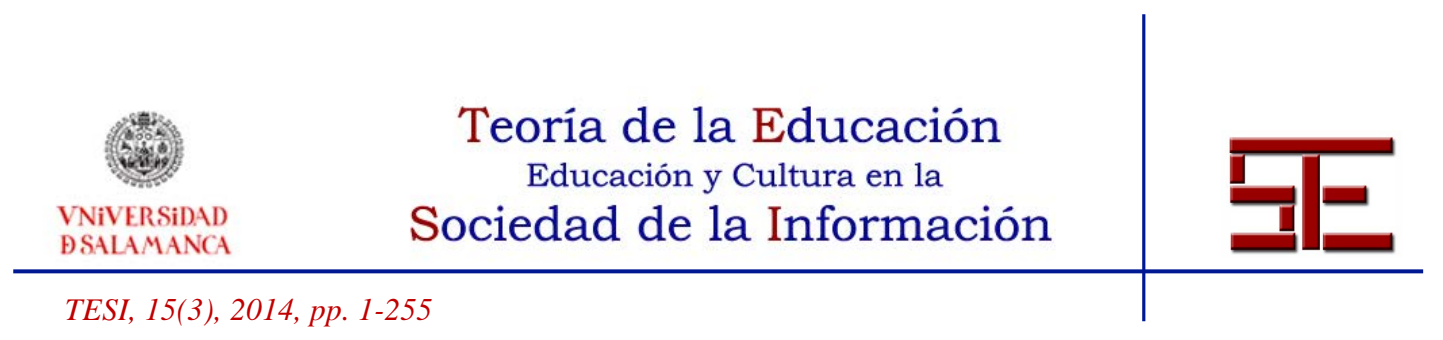

grado de conocimiento más profundo.

Las sesiones en el aula permiten corregir los fallos detectados y aplicar una retroalimentación sobre la marcha en el desarrollo de la actividad, ayudan a identificar errores lógicos y de procedimiento y a comparar y discriminar entre diversas soluciones. Aprenden distintas alternativas de resolución para un mismo problema. Por otra parte, se fomenta la asistencia a las tutorías, permitiendo al alumno plantear todas las dificultades que se va encontrando para realizar las tareas.

\subsubsection{Grupo $G 3$}

En las asignaturas de Termodinámica y de Transmisión del Calor correspondientes al grupo G3 de Complementos Formativos se ha aplicado la técnica de ABP de una forma más estricta. Estos estudiantes no necesitan demasiados refuerzos externos ya que encuentran satisfacción en comprobar su dominio de las tareas; la misma realización de las actividades de aprendizaje les resulta motivadora.

Se planifican en el transcurso del semestre diversas tareas consistentes cada una en la realización de una colección de tres o cuatro problemas que los alumnos deben resolver y entregar en un plazo determinado. Las tareas están diseñadas para ser trabajadas en grupos de 2 o 3 compañeros fuera del aula. Ellos son los que deben decidir qué parte de la materia necesitan estudiar para poder resolverlos. El profesor atiende a los grupos en sesiones de tutorías individuales y grupales controlando el avance de cada grupo y aconseja sobre las decisiones que adoptan facilitando instrucciones para poder continuar la tarea. Señala los errores que han podido cometer o sugiere la parte del tema que deben profundizar más para conseguir entender los problemas.

\subsection{Los Laboratorios}

El trabajo en el laboratorio es esencial para el aprendizaje en la mayoría de las asignaturas. Esta metodología permite adquirir conocimientos y habilidades que se aproximan al método científico, tales como la observación, el control de variables, los diagramas, la representación de los resultados de forma gráfica, su análisis y las conclusiones.

El estudiante tiene a su disposición una guía de las prácticas que debe realizar en cada sesión de laboratorio. El material de apoyo se elaboró por un grupo de profesores que impartían el laboratorio, fruto de la inestimable experiencia a lo largo de años y que sigue actualizándose gracias a la retroalimentación que se produce con los comentarios de los propios alumnos.

Las prácticas de laboratorio se abordan de manera diferente según el tipo de alumnos a los que va dirigido. Con los estudiantes del G1 la enseñanza se hace muy dirigida a

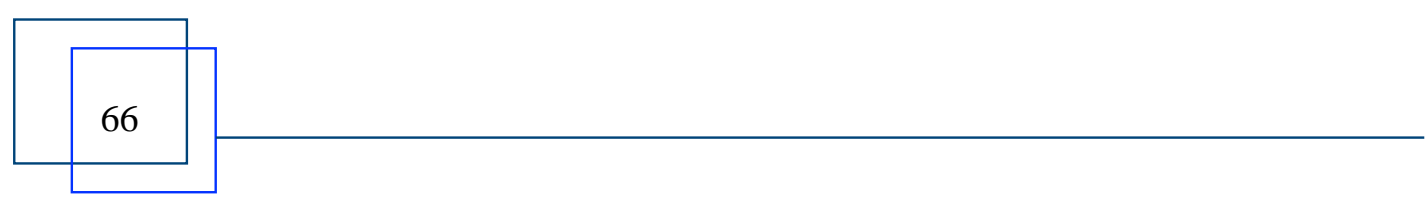




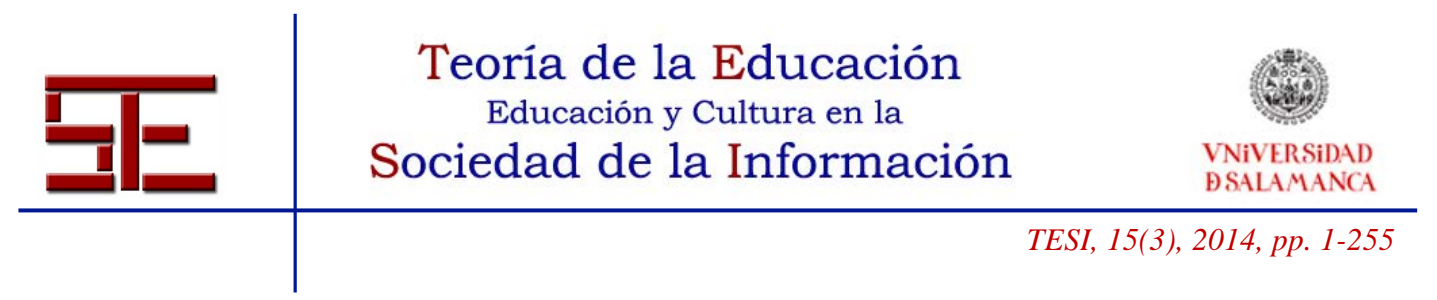

través de los guiones pues están confeccionados de manera que se va dirigiendo al alumno paso a paso para la correcta toma de datos experimentales mediante explicaciones adecuadas, confección de tablas, etc. Cada guion comienza con una introducción de los fundamentos en que está basada la experiencia y se complementa con espacios en blanco para realizar los cálculos pertinentes y anotar los resultados.

Aunque su estructura se mantiene en todos los guiones, las primeras prácticas están muy dirigidas de manera que el alumno empieza a organizar el trabajo experimental en forma de tablas, donde aprenden que no debe faltar en ninguna columna las magnitudes con sus unidades correspondientes, las medidas se deben anotar con la precisión adecuada al instrumento utilizado y donde asimilan que el orden en las anotaciones efectuadas es primordial para obtener unos resultados coherentes.

En cada sesión de laboratorio se plantea al alumno cuestiones previas relacionadas con el experimento en cuestión que deben resolver en el transcurso de la realización de la práctica y otras a resolver una vez realizada la experiencia y que deben entregar en la siguiente sesión además de tener completados todos los resultados.

Como ejemplo se muestra en la Tabla 2 el "plan de actividades" de una práctica del laboratorio de Física I. Todas las prácticas se realizan en pequeños grupos de 2 o 3 compañeros y las sesiones presenciales en el laboratorio tienen una duración de 1 hora y media.

Tabla 2. Plan de Actividades en una práctica de laboratorio de Física I.

PRÁCTICA: Medida de pequeñas longitudes

\section{SESIÓN PRESENCIAL}

\section{PROFESOR:}

En esta práctica el profesor introduce la teoría de errores centrándose en las medidas directas, da instrucciones de cómo recoger las medidas experimentales de una forma ordenada mediante la elaboración de tablas y enseña a manejar pequeños instrumentos de medida como el calibre $y$ el tornillo micrométrico.

\section{ALUMNOS:}

Los alumnos aprenden a manejar estos instrumentos midiendo el espesor de una lámina y las dimensiones de un cilindro hueco para, posteriormente, conocer su volumen. Además deberán recopilar en forma de tablas todas las medidas realizadas.

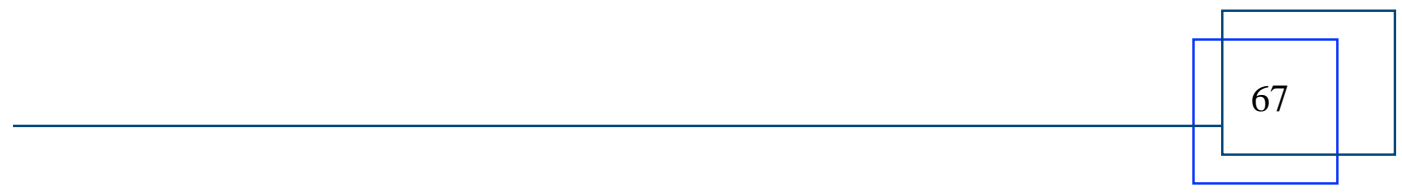




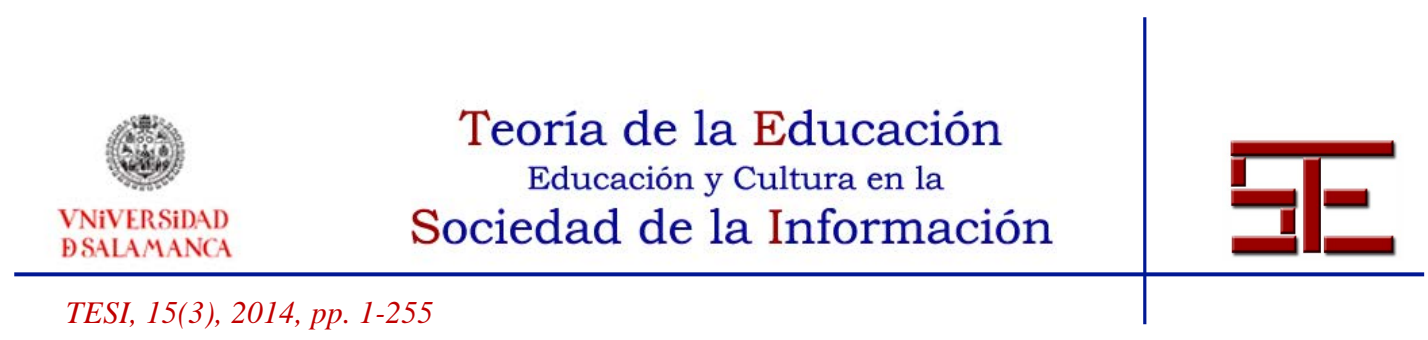

\section{SESIÓN NO PRESENCIAL}

Ya fuera del laboratorio se estima una dedicación de unas 2 horas de trabajo individual, donde el alumno debe realizar las siguientes tareas sobre la experiencia: estudio de lo visto en la clase, cálculo de errores de las medidas realizadas y resolución de las cuestiones planteadas; además deberá leer el fundamento teórico de la siguiente práctica y un recurso que tienen disponible en la plataforma institucional (b- learning) sobre la confección de gráficos (aspecto que se introduce en la siguiente sesión de laboratorio).

Los laboratorios de los grupos G2 y G3 no son tan dirigidos. Las prácticas se realizan en sesiones de 2 horas con grupos reducidos de 2 o 3 alumnos. Aunque también disponen de un guía orientadora de la experiencia esta no es demasiado explícita. Al finalizar cada sesión el grupo debe elaborar un informe de la experiencia que se entregará en la siguiente sesión de prácticas. El informe debe contener, entre otros, los objetivos, un fundamento teórico no muy extenso, consecuencia de una investigación bibliográfica, presentación adecuada de los datos medidos y un análisis y crítica de los resultados obtenidos.

Trabajar de forma cooperativa fomenta la relación entre compañeros. Esta estrategia permite desarrollar competencias en destrezas técnicas, en el manejo de procedimientos y uso de equipos, en el trabajo en equipo, la comunicación oral y escrita, y en pensamiento analítico y sintético.

\subsection{Los Trabajos Individuales}

Los programas de Física I y Física II son muy extensos y el tiempo insuficiente para hacer un poco de historia en cada tema con la intención de dar una idea de la evolución del trabajo realizado por los científicos. A través de la historia de un descubrimiento científico los alumnos aprenden que la relación entre teoría y práctica en Física no es simple y que depende de circunstancias históricas particulares en un momento dado. De este modo los alumnos verán la Física como una búsqueda abierta del conocimiento y ello permite estimular el interés por la asignatura. Los alumnos aprenden que el progreso en la Física está fuertemente ligado a las innovaciones técnicas. La historia de la Física puede transmitir a los alumnos la naturaleza de la creatividad científica. Como norma, los profesores que imparten estas asignaturas hacen referencia al personaje que dio origen a un principio o ley. Se planifican una serie de trabajos, para la asignatura de Física I, por ejemplo al estudiar el tema de Mecánica de Fluidos, deben buscar la bio- 


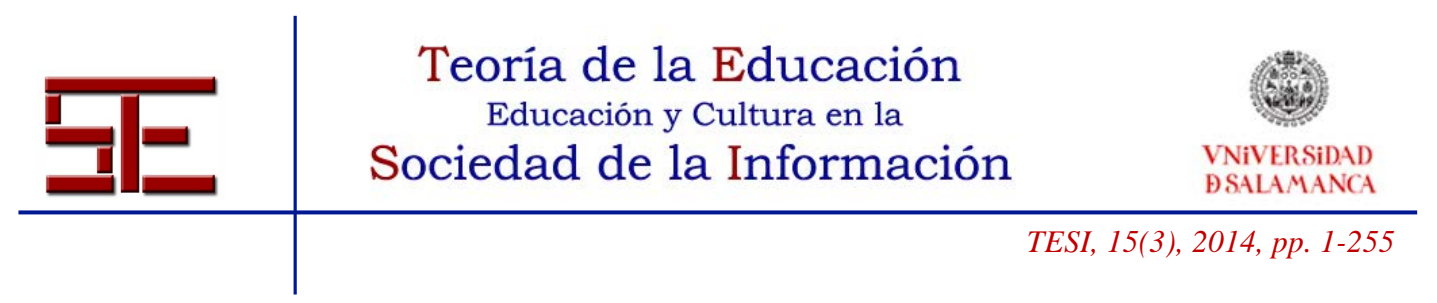

grafía de Daniel Bernouilli y desarrollar el teorema de Bernouilli con alguna de sus aplicaciones. Después de entregar los trabajos y de ser revisados por el profesor, se planifican exposiciones en el aula por algunos alumnos voluntarios.

En Física II, el profesor presenta unas referencias históricas al comenzar cada uno de los temas del programa y los estudiantes deben buscar la biografía y el trabajo de científicos tales como Coulomb, Gauss, Volta, Faraday, Edison, Tesla, etc., todos ellos relacionados con el tema estudiado. Estas actividades consiguen motivar especialmente a una buena parte del grupo.

\subsection{Los Audiovisuales}

La introducción de nuevas metodologías docentes en el aula tiene como objetivo incidir en la mejora de la motivación de los estudiantes. Un ejemplo de ello es la incorporación de herramientas multimedia en la exposición de asignaturas tradicionalmente impartidas mediante el método de la lección magistral.

La puesta en práctica de esta innovación docente ha consistido en la preparación de temas de las asignaturas de primer curso, en formato PowerPoint, donde se incluyen conceptos teóricos, figuras, desarrollos matemáticos, simulaciones y videos para facilitar su comprensión y aplicación. La preparación de los audiovisuales ha corrido a cargo de un alumno becario de apoyo bajo la supervisión y con el asesoramiento de los profesores. Los audiovisuales acompañan a los contenidos que se presentan en clase durante el desarrollo de la lección correspondiente y además está a disposición de los alumnos en la plataforma Moodle de la asignatura como ayuda a su trabajo autónomo.

En un audiovisual preparado para la asignatura de Física I, correspondiente al tema de Mecánica de Fluidos, se han incluido aspectos que los estudiantes conocen al haber buscado información previamente. Se muestran imágenes sobre aplicaciones del Principio de Pascal, por ejemplo el sistema de frenado de coches o los sistemas hidráulicos de diferente maquinaria (excavadora, carga y descarga de camiones, etc.) y aplicaciones del Teorema de Bernouilli, acercando el temario a la realidad. Se hace referencia a prácticamente todos los contenidos de dicho tema.

Un segundo audiovisual, correspondiente al tema de Oscilaciones y Ondas, incluye videos como la caída del "puente de Tacoma", explicando las oscilaciones forzadas y el fenómeno de resonancia, aportando además, aplicaciones interactivas que facilitan su comprensión. En esta presentación se añade un "applet" sobre Oscilaciones Forzadas (Franco, 1998-2009), donde se observa de forma interactiva lo que ocurre con un péndulo al variar el coeficiente de amortiguamiento, la amplitud, la posición inicial y la frecuencia de la fuerza oscilante. La parte correspondiente al estudio de las ondas se ha completado con datos sobre ondas sísmicas, incluyendo el último terremoto ocurrido en Haití (enero 2010). 


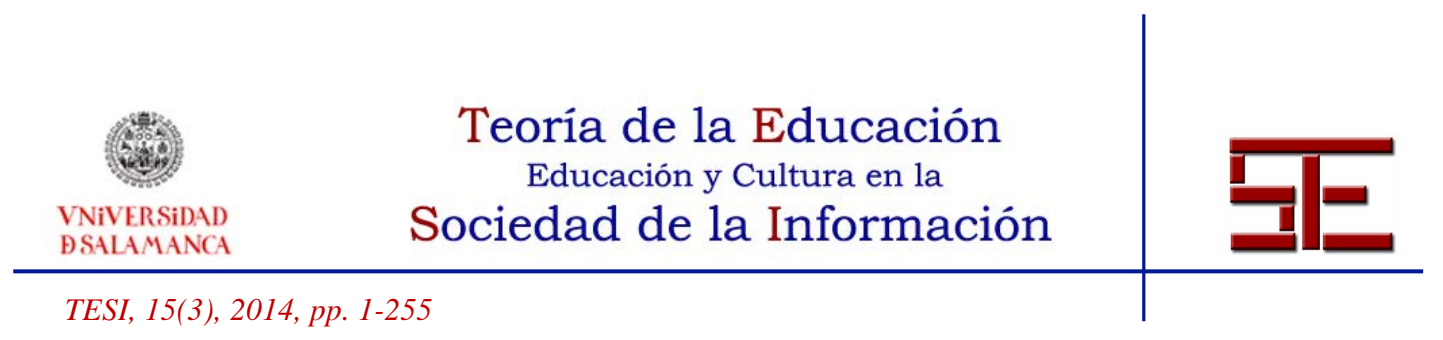

En la exposición de la asignatura de Física II se han realizado tres audiovisuales para los temas de Electrostática, de Electromagnetismo, en el que se incluyó un vídeo sobre el LHC o "Gran Colisionador de Hadrones" y del tema de Óptica, que permite visualizar y comprender el trazado de imágenes para los distintos elementos ópticos: espejos y lentes. Asimismo se preparó un audiovisual sobre el láser y sus aplicaciones industriales para mejorar la comprensión de la práctica de Óptica del laboratorio de Física II. En esta presentación, además de explicar el funcionamiento del láser, se daban una serie de aplicaciones recientes en ámbitos como la medicina, aplicaciones industriales, en informática y comunicaciones, meteorología y medio ambiente, en entretenimiento y en aplicaciones comunes.

Como principales ventajas de estas exposiciones audiovisuales cabe destacar que proporcionan una visión clara y general del tema, de este modo los gráficos y figuras son más precisos cuando se trata de conceptos de especial complejidad y los videos y gráficos animados ayudan en la exposición y comprensión de los temas.

La metodología docente empleada es altamente motivadora en el sentido de que fomenta en el alumnado una actitud activa favoreciendo la comunicación entre profesor y alumno y con ello la discusión en el aula. Además fomenta la actitud crítica frente a la información recibida a través de los medios audiovisuales.

\subsection{Las Experiencias de Cátedra}

Esta actividad desarrollada en el aula se realiza en los grupos de primer curso. Durante el transcurso de cada unidad temática el profesor prepara un "juguete didáctico" que presenta y explica a los alumnos al finalizar el tema, involucrándoles con preguntas sobre el funcionamiento y su relación con la materia estudiada. Estas experiencias de "cátedra" se fabrican íntegramente con material casero reciclable y son muy fáciles de reproducir fuera del aula. Esta actividad resulta muy atractiva para el grupo y les ayuda a comprender y afianzar conceptos, consiguiendo encontrar la Física en la vida cotidiana.

\section{RESULTADOS}

Cuando el profesor sabe motivar a los estudiantes, estos suelen conseguir la disposición y la madurez para aprender y generalmente se estimula su responsabilidad. La motivación y el aprendizaje están relacionados recíprocamente y el rendimiento académico es consecuencia, en cierta medida, de la motivación.

Se ha realizado un estudio del rendimiento académico para las 4 asignaturas presentadas en este trabajo donde se han aplicado estrategias motivadoras. En todas ellas se han

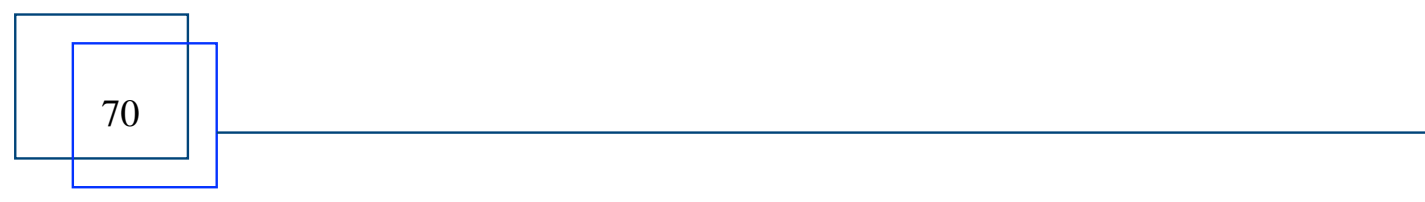




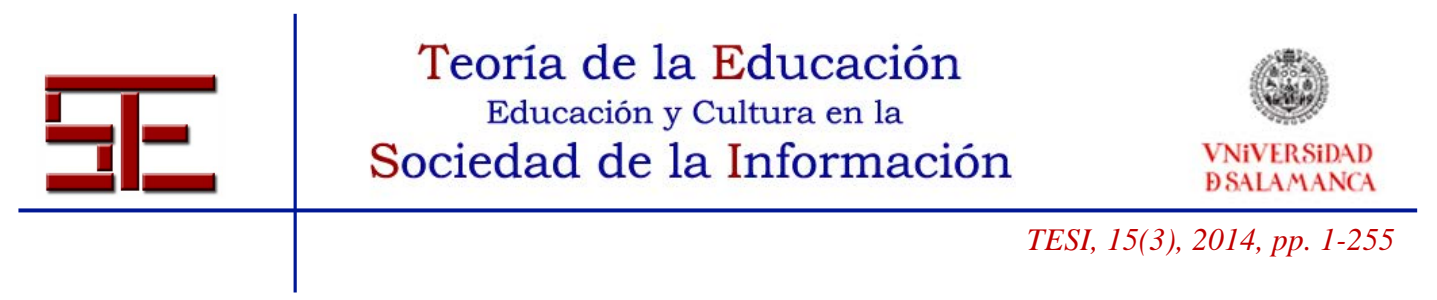

analizado los porcentajes de eficiencia, de éxito y de absentismo. La tasa de eficiencia se define como la relación entre el número de aprobados y el total de matriculados; la tasa de éxito como la relación entre el número de aprobados y el total de presentados; y finalmente, la tasa de absentismo se obtiene de dividir el número de no-presentados entre el total de matriculados.

Para las asignaturas de primer curso, es decir, Física I y Física II, ya se presentaron las tasas de éxito durante el curso 2011-12 en un trabajo previo realizado por los autores (Camarasa et al. 2013). Ahora en la Tabla 3 y Tabla 4 se muestra el rendimiento académico de estas asignaturas impartidas en los Grados de Mecánica (GID) y Diseño Industrial (GID) donde se ha ampliado el estudio a las tasas de eficiencia y absentismo y se han analizado todos estos parámetros desde que se implantó el nuevo Plan de Estudios en el año 2010.

Se ha denominado genéricamente grupo $M$ aquel en el que se ha trabajado con actuaciones motivadoras en el aula y está compuesto por una combinación de alumnos de ambos Grados; además, se realiza una comparación de los resultados académicos de este grupo con el global (incluido el $M$ ) de la misma titulación.

Tabla 3. Rendimiento académico. FÍSICA I.

\begin{tabular}{lllll}
\hline Curso & Grupo (Alum.) & Eficiencia & Éxito & Absentismo \\
\hline $\mathbf{2 0 1 0 - 1 1}$ & Global (104) & $62 \%$ & $67 \%$ & $8 \%$ \\
& $M(21)$ & $81 \%$ & $81 \%$ & 0 \\
\hline $\mathbf{2 0 1 1 - 1 2}$ & Global (117) & $49 \%$ & $51 \%$ & $5 \%$ \\
& $M(20)$ & $60 \%$ & $71 \%$ & $15 \%$ \\
\hline $\mathbf{2 0 1 2 - 1 3}$ & Global (123) & $55 \%$ & $59 \%$ & $6 \%$ \\
\hline & $M(21)$ & $68 \%$ & $71 \%$ & $4 \%$ \\
\hline GI Diseño y Desarrollo de Producto & & \\
\hline Curso & Grupo (Alum.) & Eficiencia & Éxito & Absentismo \\
\hline 2010-11 & Global (53) & $76 \%$ & $80 \%$ & $6 \%$ \\
\hline
\end{tabular}




\begin{tabular}{|c|c|c|c|c|}
\hline 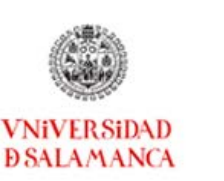 & \multicolumn{3}{|c|}{$\begin{array}{c}\text { Teoria de la Educación } \\
\text { Educación y Cultura en la } \\
\text { Sociedad de la Información }\end{array}$} & \\
\hline \multicolumn{4}{|c|}{ TESI, 15(3), 2014, pp. 1-255 } & \\
\hline & $M(24)$ & $84 \%$ & $92 \%$ & $7 \%$ \\
\hline \multirow[t]{2}{*}{ 2011-12 } & Global (60) & $55 \%$ & $58 \%$ & $5 \%$ \\
\hline & $M(26)$ & $53 \%$ & $62 \%$ & $1 \%$ \\
\hline \multirow[t]{2}{*}{$2012-13$} & Global (69) & $61 \%$ & $64 \%$ & $4 \%$ \\
\hline & $M(30)$ & $69 \%$ & $69 \%$ & 0 \\
\hline
\end{tabular}

Al analizar los datos de Física I, según se observa en la Tabla 3, el grupo $M$ presenta unas tasas de éxito ligeramente superior que las de la titulación completa en ambos Grados (GIM y GID), aunque más acusada en GIM, en torno al 25\% que en GID (10\% superior). Quizás esta diferencia sea debida a que la nota exigida en esta Escuela para cursar el GID es la más alta entre todos los Grados; estos estudiantes parecen estar motivados y no necesitan demasiados refuerzos externos. Entre paréntesis se especifica el número de alumnos matriculados en los diferentes años académicos. En el grupo $M$ aunque se presentan los porcentajes del rendimiento académico de los alumnos separados por titulación, no se debe olvidar que el grupo está formado por alumnos de ambos Grados (GIM y GID).

Con respecto a Física II, la Tabla 4 nos muestra los resultados académicos de dos cursos. La tendencia de unas tasas de éxito superior en el $M$ se manifiesta claramente en el GID (en torno al 16\%); parece que se empieza a percibir el beneficio que supone realizar un esfuerzo. Para el caso de GIM es a partir del curso 2011-2012 cuando los estudiantes empiezan a notar la utilidad de una metodología activa en el aula.

Es interesante señalar que desde que comenzaron a impartirse los Grados en el curso 2010-2011, estas dos asignaturas tienen un alto porcentaje de renuncias a la "evaluación continua", causado probablemente por los porcentajes asignados a la evaluación continua y al examen final para la obtención de la calificación final y al tipo de exámenes. Los datos del rendimiento académico reflejados en las tablas anteriores hacen referencia a las convocatorias ordinarias, pero no se hace distinción entre "evaluación continua" o "solo prueba final".

Tabla 4. Rendimiento académico (\%). FÍSICA II.

\begin{tabular}{|lllll}
\hline Curso & Grupo (Alum.) & Eficiencia & Éxito & Absentismo \\
\hline 2010-11 & Global (101) & 49 & 54 & 11 \\
\hline
\end{tabular}

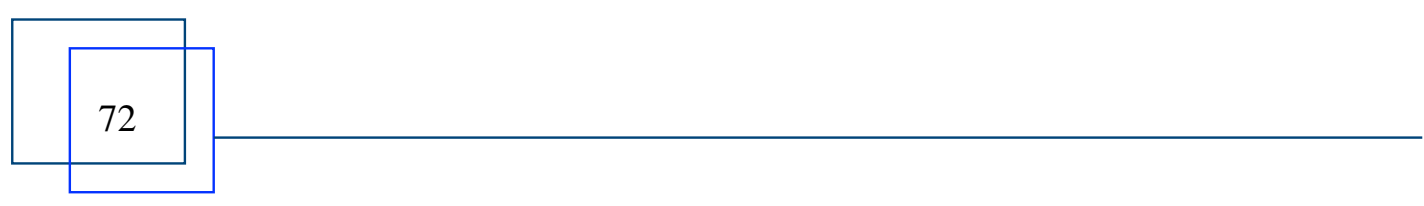




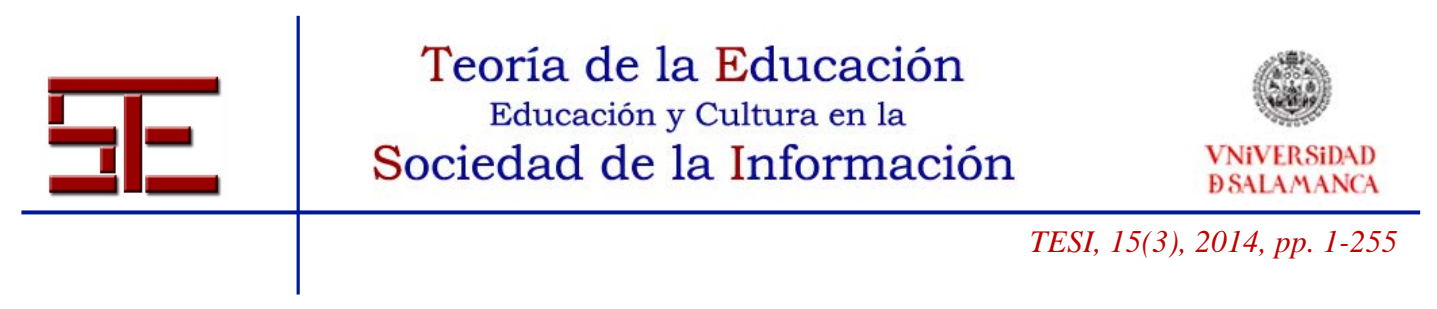

\begin{tabular}{lllll} 
& $M(21)$ & 48 & 47 & 0 \\
2011-12 & Global (138) & 50 & 59 & 15 \\
& $M(20)$ & 65 & 72 & 10 \\
\hline
\end{tabular}

GI Diseño y Desarrollo de Producto

\begin{tabular}{lllll}
\hline Curso & Grupo (Alum.) & Eficiencia & Éxito & Absentismo \\
\hline 2010-11 & Global (67) & 45 & 48 & 6 \\
& $M(22)$ & 52 & 57 & 8 \\
\hline \multirow{2011-12}{*}{} & Global (70) & 46 & 52 & 11 \\
& $M(26)$ & 56 & 59 & 6
\end{tabular}

La evaluación continua, aunque se califica, pretende ser más bien una evaluación formativa, donde el alumno paulatinamente vaya progresando en su aprendizaje. Sin embargo, en el grupo $M$ dicho porcentaje de renuncias ha sido prácticamente nulo (menor del 2\%). Probablemente ello es debido en gran medida a la alta motivación del grupo, aspecto que se vio reflejado en la encuesta que realizaron.

En las Tablas 5 y 6 se presentan los resultados del rendimiento académico (tasas de eficiencia, éxito y absentismo) para las asignaturas de Termodinámica y de Transmisión del Calor correspondientes al $2^{\circ}$ curso. Como ya se ha mencionado anteriormente, ambas asignaturas se imparten en todos los Grados con metodologías activas utilizando algunas de las estrategias motivadoras en el aula descritas en este artículo.

En los resultados mostrados en dichas tablas están incluidos los correspondientes a los estudiantes de Grado (G2) y de Complementos Formativos (G3). Este último grupo de alumnos no es muy numeroso, en torno a 10 o 15 por curso y se encuentran repartidos entre todas las titulaciones. Su motivación es muy alta y ello se ve reflejado en el alto porcentaje de éxito que alcanzan, que ronda prácticamente el $100 \%$.

Se observa que el rendimiento académico es muy alto en todos los grupos a pesar de ser asignaturas no excesivamente sencillas. Mediante la evaluación continua que se desarrolla a lo largo del semestre se aprecia la evolución de aprendizaje en los diferentes grupos. Prácticamente la totalidad de los alumnos siguen la asignatura correspondiente mediante "Evaluación continua" en todos ellos. Se planifican 3 controles parciales y un

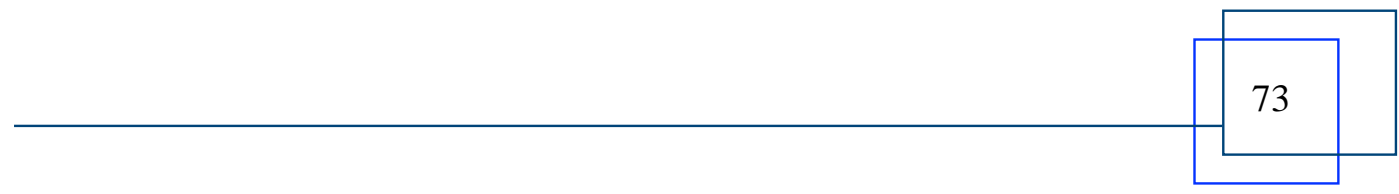




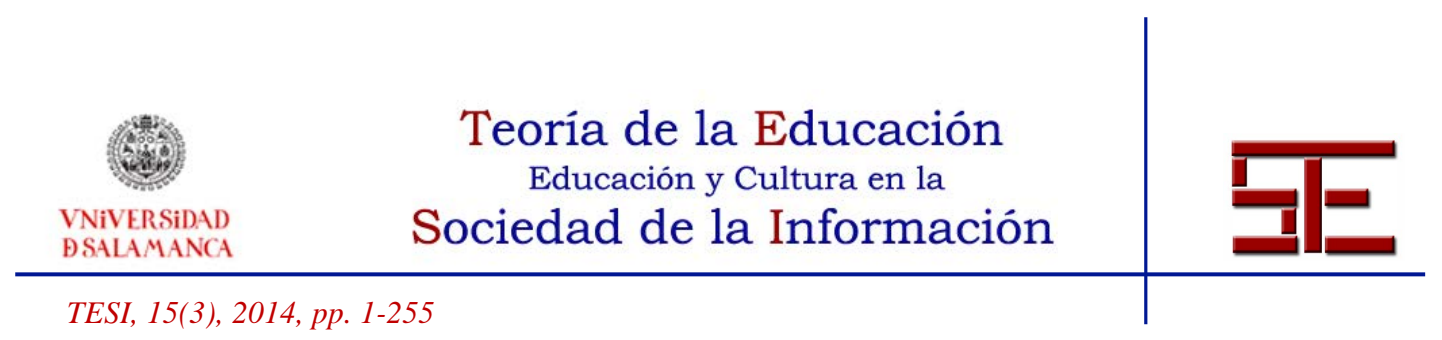

examen final que incluye la totalidad de la asignatura. A pesar de que en el primer control el porcentaje de aprobados suele ser muy bajo, a medida que se va desarrollando la asignatura se aprecia un progreso significativo en el rendimiento académico.

Tabla 5. Rendimiento académico (\%). TERMODINÁMICA.

\begin{tabular}{|lllll|}
\hline Curso & Grupo & Eficiencia & Éxito & Absentismo \\
\hline 2011-12 & GIM & 78 & 80 & 2 \\
& GIE & 92 & 94 & 2 \\
& GIA & 72 & 74 & 2 \\
\hline 2012-13 & GIQ & 64 & 64 & 0 \\
\hline & GIE & 83 & 87 & 5 \\
\hline & GIA & 83 & 91 & 0 \\
\hline & GIQ & 68 & 68 & 5 \\
\hline
\end{tabular}

Tabla 6. Rendimiento académico (\%). TRANSMISIÓN DEL CALOR.

\begin{tabular}{|lllll|} 
Curso & Grupo & Eficiencia & Éxito & Absentismo \\
\hline 2011-12 & GIM & 65 & 67 & 3 \\
& GIE & 83 & 84 & 1 \\
& GIA & 91 & 91 & 0 \\
& GIQ & 86 & 89 & 2 \\
& GID & 92 & 92 & 0 \\
\hline
\end{tabular}




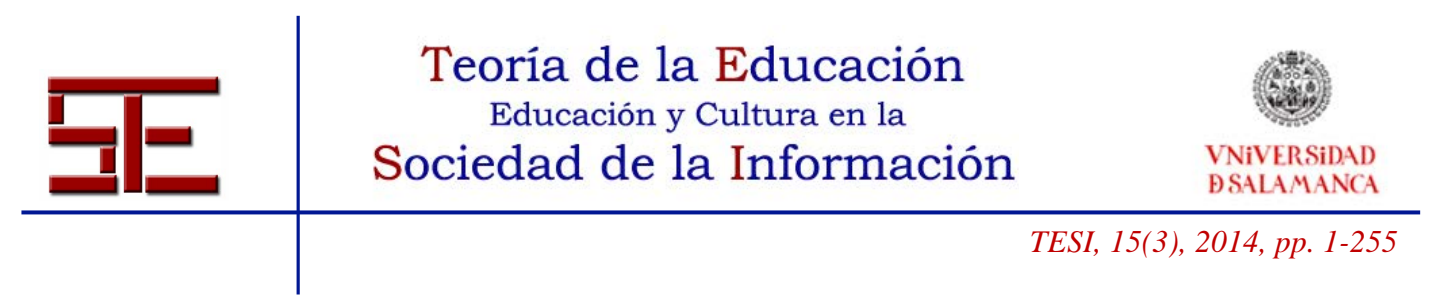

\section{CONCLUSIONES}

A la vista de los resultados mostrados en este trabajo y aunque las mayores tasas de éxito en las asignaturas de Física I y Física II se alcanzaron durante el curso 2010-2011, probablemente debido a que el primer año en que se implantaron los nuevos Grados había un alto porcentaje de alumnos procedentes del Plan de estudios anterior (repetidores), se puede deducir una tendencia hacia unas tasas de éxito mayores en aquellos grupos donde se trabaja con metodologías motivadoras. Al utilizar en el aula metodologías que hagan trabajar al alumno su rendimiento académico va mejorando gradualmente.

La introducción de nuevas metodologías en el aula involucra más al alumno en su propio proceso de aprendizaje, convirtiéndose el profesor en facilitador del mismo. Es importante recordar que quien produce el aprendizaje es el estudiante, no el profesor y nadie aprende si no le mueve alguna razón. Si el profesor está motivado para enseñar se encuentra en disposición de motivar a sus alumnos con el consiguiente beneficio académico.

Aprender a motivar significa estimular la autonomía de los estudiantes y no la tendencia existente a ejercer un mayor control sobre ellos.

Si un alumno alcanza sus metas de aprendizaje, ello le motiva para establecer nuevas metas y desafíos. Es importante que los estudiantes perciban el valor del trabajo y las actividades de aprendizaje como caminos para adquirir capacidades y habilidades.

Lo más decisivo para incrementar la motivación y el interés de los alumnos por aprender no son los conocimientos del profesor sobre la materia que imparte, sino los conocimientos sobre las distintas estrategias didácticas.

Las estrategias de aprendizaje ayudan a promover la progresiva autonomía de los estudiantes. El profesor debe definir nuevas formas de trabajar utilizando en el aula todos los recursos disponibles, empleando diferentes estilos en los diversos momentos del proceso de enseñanza para llegar al mayor número de alumnos.

La evaluación no se debe percibir únicamente como instrumento de medida del éxito o fracaso, sino como una herramienta orientadora del proceso de desarrollo y mejora personal. Este punto de vista va unido al esfuerzo y al trabajo, lo que provoca un aumento de la motivación.

Para finalizar podríamos resumir las conclusiones de este trabajo citando una frase del Físico Albert Einstein: "Nunca enseño a mis alumnos; solo intento proporcionarles las condiciones para que puedan aprender"

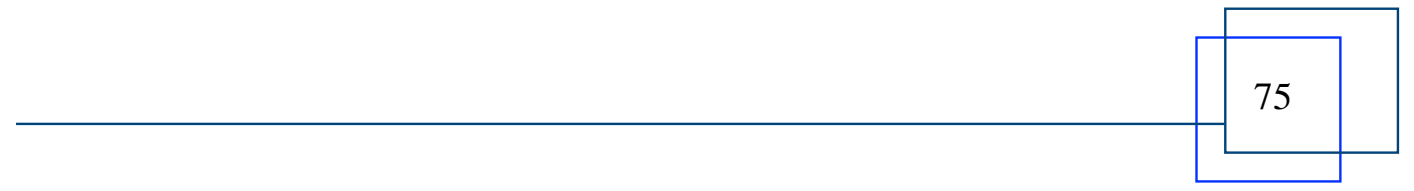




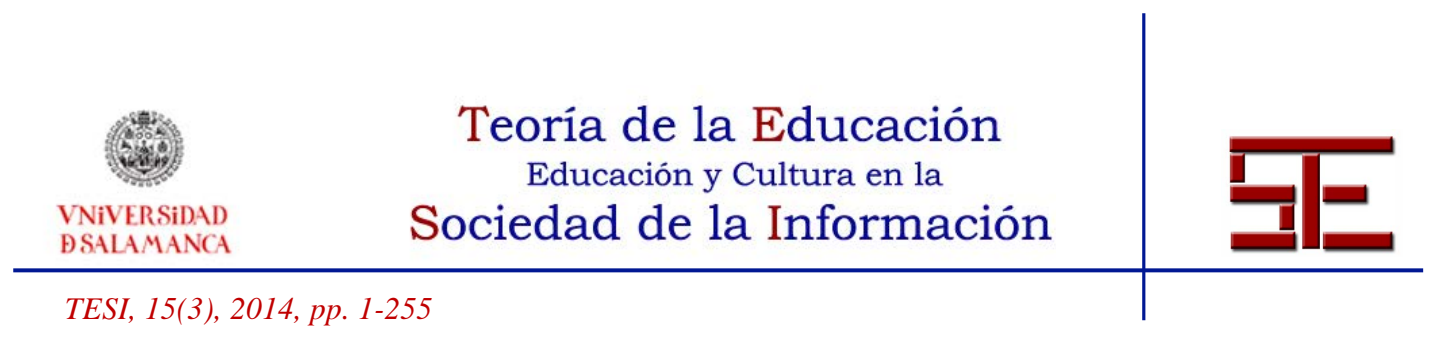

\section{BIBLIOGRAFÍA}

Alonso, J. (2005). Motivar en la escuela, motivar en la familia. Morata.

Asensio (coord.) (2012). Las competencias de los profesionales de la educación hoy. La transformación de la práctica educativa. En García Aretio, L. (ed.), Sociedad del conocimiento y Educación (pp. 193-213). Madrid: UNED.

Barkley, E., Croos, P., y Major, C. (2007). Técnicas de Aprendizaje Colaborativo. Manual para el profesorado. Colección MEC, Madrid.

Beltrán, J., (1995). Procesos, estrategias y técnicas de aprendizaje. Madrid: Síntesis/Psicología.

Bernard, J. A. (1999). Estrategias de aprendizaje. Madrid: Bruño.

Boza, A., Toscano, M. O. (2012). Motivos, actitudes y estrategias de aprendizaje: Aprendizaje motivado en alumnos universitarios. Revista Profesorado, 16(1), pp. 125142.

Burguet, M. y Buxarrais, M. R. (2013). La eticidad de las TIC. Las competencias transversales y sus paradojas. Revista Teoría de la Educación: Educación y Cultura en la Sociedad de la Información, 14(3), 87-100 [Fecha de consulta: 18/01/2014]. Disponible en:

$<$ http://campus.usal.es/ revistas_trabajo/index.php/revistatesi/article/view/11352/11782 $>$.

Buxarrais, M.,Ovide, E. (julio - diciembre, 2011). El impacto de las nuevas tecnologías en la educación en valores del siglo XXI. Sinéctica, 37. Extraído el 30 de enero de 2013, de

<http://www.sinectica.iteso.mx/?seccion=articulo\&lang=es\&id=520_el_impacto_de_las _nuevas_tecnologias_en_la_educacion_en_valores_del_siglo_xxi $>$.

Camarasa, M., Bravo, A., García, J. M., Montero, R. (2013). Hacia un aprendizaje más eficaz. II Congreso Internacional sobre Aprendizaje, Innovación y Competitividad. CINAIC 2013. Fundación General de la Universidad Politécnica de Madrid. Libro de Actas. (pp. 123-128).

Franco, A. (1998-2009). Curso Interactivo de Física en Internet, <http://www.sc.ehu.es/sbweb/fisica_/>.

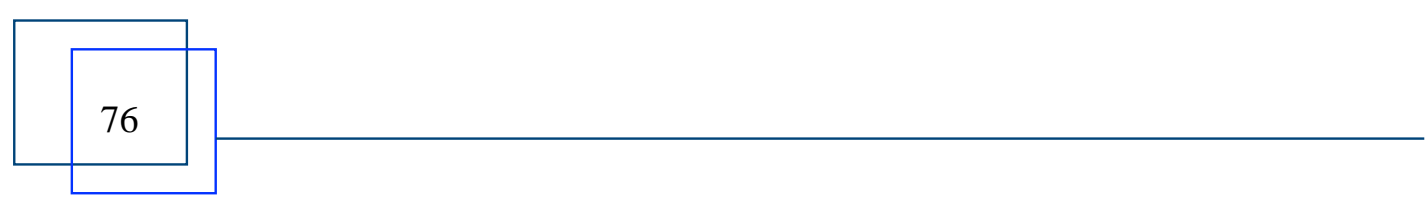




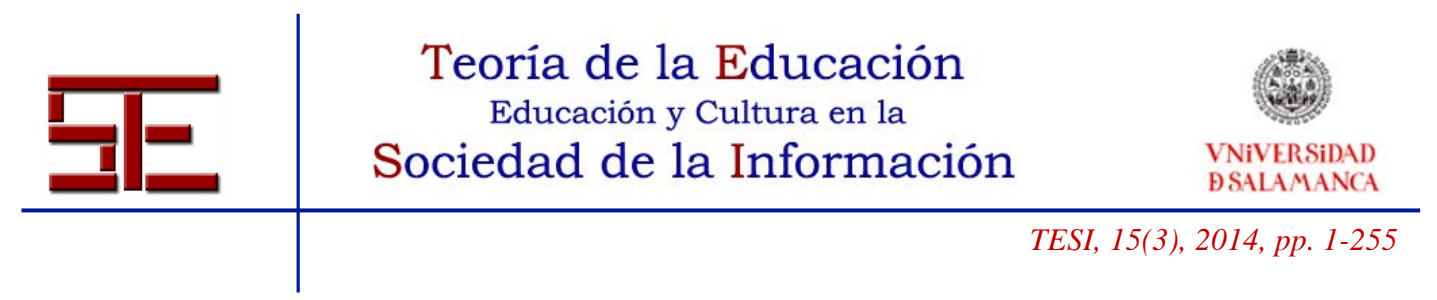

Gallardo, B. (2000). Procedimientos. Estrategias de aprendizaje. Su naturaleza enseñanza y evaluación. Valencia: Tirant lo Blanch.

García, F. (2008). Motivar para el aprendizaje desde la actividad orientadora. CIDE. Ministerio de Educación y Ciencia.

Gargallo, B., Suárez, J. M. y Pérez, C., (2009). El cuestionario CEVEAPEU. Un instrumento para la evaluación de las estrategias de aprendizaje de los estudiantes universitarios. Revista Relieve, 15(2), pp. 1-31. Disponible en: <http://www.uv.es/RELIEVE/v15n2_5.htm>.

González, J. y Wagener, R. (eds.) (2008). La contribución de las Universidades al proceso de Bolonia - Una introducción. Bilbao: Universidad de Deusto.

González, A. (2002). Motivación Académica: Teoría, Aplicación y Evaluación. Pirámide.

Morales, P., (2009). Ser profesor: una mirada al alumno. Guatemala: Univ. Rafael Landivar

Monereo, C. y Castelló, M. (2001). Las estrategias de aprendizaje. Cómo incorporarlas a la práctica educativa. Barcelona: Edebé.

Montico, S. (2004). La motivación en el aula universitaria: ¿una necesidad pedagógica? Revista Ciencia, Docencia y Tecnología, 29, Año XV, pp. 104-112.

Morín, E. (2002). La cabeza bien puesta. Bases para una reforma educativa. Edit. Nueva Visión. Bs. As.

Romero, M., Pérez, M. (2009). Cómo motivar a aprender en la Universidad: Una estrategia fundamental contra el fracaso académico en los nuevos modelos educativos, Revista Iberoamericana de Educación, 51, pp. 87-105.

Sepúlveda, F. y Rajadell, N. (coord.) (2001). Los procesos formativos en el Aula: Estrategias de enseñanza-aprendizaje. Didáctica General para Psicopedagogos. (pp. 465-525). Madrid: UNED

Soler, A. (2012). La apatía del alumno. Hipo tesis. Archivo digital UPM. Serie alfabética (12). 9 - 9. 


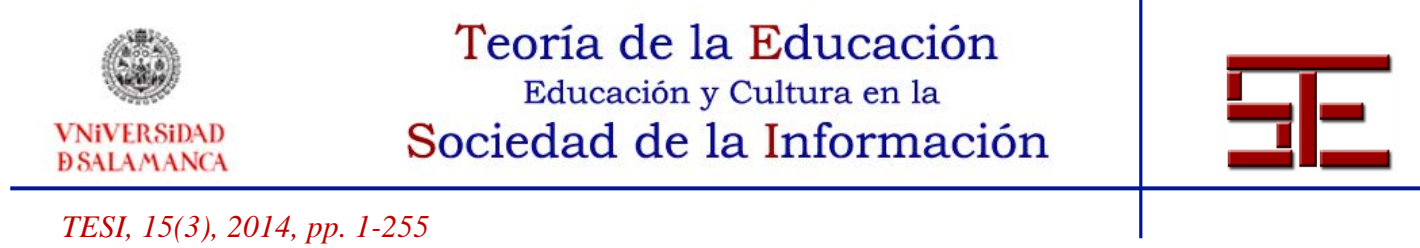

Torre, J. C. (2007). La Enseñanza centrada en el aprendizaje: estrategias útiles para el profesorado. Barcelona: Octaedro. 